\title{
Rehbein, Boike y Souza, Jessé (2014): Ungleischheit in kapitalistischen Gesellschaften. Weinheim und Basel: Beltz Juventa, 228 pp. ISBN: 978-3-7799-2947-5.
}

Analizar la sociedad, lo visible y lo oculto, es un objetivo que se vienen planteando muchos autores desde la Antigüedad. Obtener datos para fundamentar esos estudios es básico desde que la sociología comenzó su andadura. El presente texto pretende cumplir ese objetivo basándose en trabajos contrastables para desarrollar una teoría de las desigualdades sociales en las sociedades actuales. La teoría tiene conexiones con las clásicas, desde Marx a Weber, Bourdieu y Luhmann, pero se diferencia incluso de ellos por el carácter empírico al relacionar sociedades de tres continentes. Esta conexión práctica con sociedades occidentales y no occidentales les permite reconocer los mecanismos, visibles pero tamizados, de creación y reproducción de las desigualdades sociales, tanto generales como básicas, igual que lo hicieron los clásicos, al mismo tiempo que los autores podían captar más adecuadamente las peculiaridades históricas, culturales y sociales de cada una de las sociedades.

Capitalismo y democracia se extienden por todo el globo terráqueo. Sin embargo, la desigualdad socioeconómica, en contra de lo esperado, no decrece, más bien aumenta. En 1999, los 358 individuos más privilegiados tenían un patrimonio que se correspondía con el de tres mil millones menos privilegiados. El diez por ciento de la población más rica disponía de dos tercios de la riqueza global. No hay ningún indicio de que la brecha se vaya a cerrar. Es más, la concentración de la riqueza económica desde el comienzo de la crisis financiera de 2008 ha aumentado. En 2010 el 93\% del crecimiento económico fue a parar a manos del porcentaje más rico de los americanos mientras que el resto, el $99 \%$, recibieron un incremento medio de 80 dólares, es decir, ni si quiera recibieron el incremento porcentual de la inflación (International Herald Tribune, 22.3.2012).

Si bien las tendencias, tanto en la opinión pública como entre los investigadores, han ido hacia una mayor atención sobre el problema, no parece que esta dedicación haya hecho que se pueda encontrar la solución. Los conceptos para la comprensión de la desigualdad parecen mayoritariamente anticuados mientras que la mayoría de las medidas prácticas llevan solamente a una mejoría parcial y cortoplacista. Los autores argumentan en el texto cómo contribuye nuestra idea heredada sobre la desigualdad a su reproducción y a la agudización del problema en la actualidad.

Los autores parten, para reconocer mejor las raíces estructurales de las desigualdades, de que la transmisión simbólica de poder se encuentra en la raíz de esa desigualdad social. Denominan poder a la distribución impersonal de posibilidades de influir la valoración social y el desarrollo de la vida. Con el concepto de símbolo, los autores quieren representarbasándose en Ernst Cassirer- todas las manifestaciones con sentido del ser humano, desde el lenguaje hasta los signos pasando por el arte. Los autores argumentan que todas las acciones humanas son transmitidas de forma simbólica y que esta transmisión es la llave para la comprensión de la sociedad. El capitalismo es ciertamente una acción que discurre, en gran medida, de forma inconsciente pero no tiene nada de natural o material sino simbólico. Sin una transmisión simbólica no existiría una bolsa de valores o el capital monetario. Así, al igual que las acciones empresariales y el dinero no tendrían ningún valor, las máquinas o la tecnología serían inservibles.

Las ciencias sociales, incluida la economía, han desarrollado modelos adecuados para la descripción de las desigualdades sociales y sus evoluciones normales. Disponemos, además, de complejas y profundas teorías sobre la desigualdad social en Occidente (Bourdieu) y podemos describir perfectamente las estructuras sociales de los países desarrollados. También disponemos de teorías de sistemas que nos permiten analizar la interrelación global de los elementos. Sin embargo, cada una de estas propuestas parte de la propagación universal del modelo de sociedad occidental y lo denomina según las características del capitalismo, democracia, modernización, diferenciación o individualismo. El eurocentrismo, que recubre todo esto, no solo es chauvinista y corto de miras en cierto sentido sino que, además, hace invisibles los mecanismos de desigualdad social.

Por otro lado y según el concepto hermenéutico, el texto oscila, al igual que lo hace Marx para El capital, de la superficie a las estructuras profundas y viceversa. En la primera parte, "El capitalismo", los autores esquematizan el mundo social de las sociedades capitalistas, tal y como lo perciben, así como el concepto asumido de sociedad tanto en el sistema simbólico cotidiano como en el científico. La segunda parte, "Desigualdad en el capitalismo", desarrolla las estructuras profundas de la desigualdad que son imprescindibles para la superficie. El argumento vuelve, en la tercera parte del libro, "Desigualdad simbólica", a la superficie para explicarla desde las estructuras profundas anteriores y mostrar los evidentes sistemas simbólicos, como elementos esenciales pero a la vez relativos y casi invisibles de sociedades capitalistas. La forma de presentar el libro exige su lectura hasta el final. Se pueden saltar partes, pero no terminarlo sin las conclusiones. 
El proceso de la configuración nos recuerda a la fenomenología de Hegel quien, en último término, quiere acoger las configuraciones en la Europa capitalista y éstas en Dios. Los elementos teológicos y teleológicos los intentó eliminar Gadamer de la propuesta dialéctica de Hegel. Por esta razón, los autores denominan a su propuesta como hermenéutica al conectar con Gadamer pero eliminando su eurocentrismo.

El mecanismo general de funcionamiento de la desigualdad en las sociedades capitalistas se basa en una jerarquía de valores ya asumida, tanto por el individuo como por los grupos sociales que forman esa sociedad. Por el contrario, el mito básico de la sociedad capitalista afirma la igualdad de todos los ciudadanos y sitúa la sociedad sobre fundamentos científicos -pero, en realidad, la sociedad sigue siendo desigual e indescifrable-. En las primeras teorías sobre el Estado, e incluso en las democracias reales, solo los "ciudadanos" eran libres e iguales mientras que la mayoría de los grupos de la sociedad (esclavos, mujeres, extranjeros $y$, en principio, incluso los trabajadores) no pertenecían a la sociedad civil y, de este modo, no eran iguales. Dentro de la sociedad precapitalista se diferenciaba entre niveles o clases sociales con diferentes derechos, llegando a excluir a las colonias de la sociedad de los iguales.

Allí donde diferentes grupos sociales fueron incluidos en la comunidad de los iguales, estos permanecieron subordinados y en desigualdad de condiciones. Con Foucault y Adorno, y estos siguiendo la idea de Durkheim, los autores afirman que las transformaciones capitalistas generaron el subjetivismo individualista que se caracteriza principalmente por la estandarización no por la singularidad, es decir, la división del trabajo contaba con cada persona pero inmersa dentro de una gran máquina, la sociedad. La desigualdad, dentro de la comunidad de los iguales, debía proceder de diferencias en la actitud ética y en las prestaciones relevantes de los individuos.

El presupuesto básico de la tradición liberal de Hobbes a Locke, del fundamento matemático de Descartes, a Galileo y a Smith, pero también identificable, en cierto sentido, hasta la antigua Grecia, hasta Platón es que todos los individuos son considerados iguales biológicamente y desde el nacimiento, debían tener las mismas oportunidades y esta idea determina las Constituciones de la mayoría de las democracias actuales. El camino recorrido hasta llegar a ellas tuvo que pagar el peaje de otorgar los derechos a un muy exclusivo y pequeño grupo dominante. Es decir, el cambio de estructura no cambió el fondo. Pero incluso después de la Revolución Francesa o Americana, la igualdad, la libertad y la fraternidad quedaron limitadas a unos pocos grupos. Cada uno de ellos desarrolló sus propias líneas de tradición.

Cada línea de tradición tiene su propia cultura, transmite diferentes habitus (Bourdieu) y se entrelaza con los diferentes sectores de las instituciones. Cada sector institucional desarrolla su propio habitus y, de esta manera, reproduce la línea de tradición. De este modo, las clases están determinadas como líneas de tradición no sólo por la posesión de capital, sino que también son culturas que abarcan ciertos y modelos de comportamiento y sistemas de símbolos muy limitados a ellos mismos y que una vez asumidos los transmiten. Como dice Edward P. Thompson, hay que interpretar las clases principalmente como culturas vivas y no como cajas, como algo cerrado.

Será Max Weber quien piense de forma distinta y vea el verdadero cambio en la revolución simbólica del protestantismo ascético. Para él fue la verdadera revolución moderna en tanto en cuanto que transformaba la conciencia de la gente $y$, por ende, la realidad externa. La voluntad férrea, la disciplina y el autocontrol fueron las armas de la Revolución y el fundamento de la sociedad moderna y del individuo liberal.

Las revoluciones sociales generan procesos de transformación cultural y las líneas de tradición dividen a diferentes generaciones, lo que llamamos "culturas sociales". Estas son, por así decirlo, diferentes capas históricas en la misma sociedad. Los cambios sociales se reflejan en el discurso, ya que tocan los sistemas simbólicos sociales. Lo cual puede llegar hasta el punto de que los padres y los niños entre sí apenas se entienden porque ya no hablan el mismo idioma. Sin embargo, una revolución no funciona de la misma manera en todas las líneas de tradición.

Cada entorno transmite a sus componentes una cultura que les predispone para determinadas instituciones y funciones en la división de actividades. Está integrada en el habitus. De este modo, el hijo de un albañil tendría una probabilidad tendente a cero como gerente general de una gran empresa y no sería elegido, con toda probabilidad, en caso de haber un concurso. Las actividades son valoradas socialmente y se las maquilla con determinadas condiciones de acceso. Incluso cuando la contratación se realiza con los criterios puramente formales, transparentes y funcionales, el que contrata clasifica al solicitante según sus cualidades y criterios que él mismo ha incorporado.

Desde la perspectiva del individuo, las estructuras sociales actúan como campos de fuerza que atraen o repelen al individuo. $Y$ desde el nacimiento se entra en un campo de fuerza, que se corresponde, en la mayoría de los casos, con el campo de fuerza de los padres o de los tutores legales o responsables. Cuanto más tiempo se esté en ese campo de fuerza más se interiorizan sus modelos de comportamiento $y$ símbolos válidos. De este modo se aprende a ser un miembro de la sociedad y a vivir en él. Al mismo tiempo, cada vez es más difícil interiorizar modelos de comportamiento y símbolos de otros entornos sociales -comenzando por la familia y pasando por un entorno cultural diferente-.

En el libro, los autores intentan mostrar la interrelación entre la revolución social, que tiene relación con la aparición del capitalismo, con la clase y 
cultura social, entorno, división de actividades y sistema simbólico. Para esto, a cada concepto se le ha atribuido un capítulo en el cual la generalidad al mismo tiempo explica y contextualiza configuraciones concretas del contexto en Brasil, Alemania, India y Laos. Los autores parten de la hipótesis, y concluyen, que su mecanismo es válido para todas las sociedades capitalistas $y$, de esta forma, para todas las formas de desigualdad social.

Para concluir, y como dicen los autores, el texto tiene una orientación teórica aunque con fundamentos empíricos. La teoría, muy bien desarrollada, manejando tanto los autores clásicos como los más modernos, introduce una línea crítica y fresca en el análisis social que posibilita la comprensión de la realidad, visible e invisible, desde un punto de vista diferente $y$ apasionante. Se echan en falta, sin embargo, los datos que soportan la teoría y para los que los autores nos emplazan a una muy próxima publicación.

Eduardo Díaz Cano Universidad Rey Juan Carlos,

Madrid, España eduardo.diaz@urjc.es Recibida: 25-08-2014 Aceptada: 19-10-2014

(c) (1) (3) 